\title{
O horror do corpo em dois contos de Gastão Cruls
}

Júlio França $a^{a}$

\begin{abstract}
Resumo
O ensaio objetiva refletir sobre os horrores relacionados ao corpo humano, ou, sendo mais específico, sobre os modos como o corpo humano é representado nas narrativas de horror. Para tanto, em um primeiro momento, situa-se a vertente do horror do corpo na tradição das narrativas que exploram o medo como prazer estético, para, em seguida, tomar como demonstração duas narrativas curtas do escritor carioca Gastão Cruls (1888-1959): “G.C.P.A." (1920) e "O espelho" (1938).

Palavras-chave: Literatura Comparada; literatura gótica; literatura de horror.
\end{abstract}


Body Horror. Not dead bodies. Your own body. And something is going very wrong. Inside. Your body is betraying you, and since it's your own body, you can't even run away.

Stuart Gordon (2012, p. 1)

1 Convém esclarecer que se entende aqui a narrativa de horror e congêneres como estruturas narrativas convencionais, com elementos recorrentes que sofrem poucas alterações de forma, mas que são renovadas continuamente por novas figurações promovidas por contextos culturais diversificados (cf. CARROLL, 1990). Uma hipótese oriunda desse entendimento é a de que seria possível identificar, nas narrativas de horror, tendências temáticas dominantes em alguns períodos históricos, que apontariam, por sua vez, para os medos e as ansiedades preponderantes em dado momento e em dado local.

\section{Introdução}

Este ensaio foi fomentado pelo convite dos professores André Cardoso e Claudete Daflon para integrar a mesa temática "Corpo obsceno", no II Seminário Interferências: Literatura e Ciência, Monstruosas Organizações, realizado no mês de setembro de 2017, no Instituto de Letras da Universidade Federal Fluminense. Como tenho me dedicado, nos últimos dez anos, às "poéticas do mal" - isto é, ao estudo de narrativas ficcionais que se caracterizam por privilegiar a representação e a expressão de aspectos negativos da experiência e do imaginário humanos -, busquei, em meu campo de pesquisa, um recorte que contemplasse o tema proposto.

$\mathrm{O}$ resultado foi este pequeno ensaio, em que se procura refletir sobre os horrores relacionados ao corpo humano, ou, sendo mais específico, sobre os modos como o corpo humano é representado nas narrativas que integram meu corpus de pesquisa. Para tanto, proponho, em um primeiro momento, situar a vertente do horror corporal na tradição das narrativas que exploram o medo como prazer estético (FRANÇA, 2017b, p. 45-52), para, em seguida, tomar como demonstração duas narrativas curtas do escritor carioca Gastão Cruls (1888-1959): "G.C.P.A." e “O espelho".

\section{A Era do Body Horror}

O termo horror do corpo aqui empregado é uma tradução possível para Body Horror, denominação dada à vertente dominante da ficção de horror cinematográfica nas últimas décadas do século XX (FIZPATRICK, 2017), sobretudo nos EUA. De um ponto de vista historiográfico ${ }^{1}$, seu auge se deu no período imediatamente posterior ao que se convencionou chamar de era do horror atômico, quando um grande número de narrativas de horror explorava, por um lado, os riscos relacionados aos mais diversos usos da energia nuclear, e, por outro, a paranoia produzida pela difusa ameaça representada 
por conquistadores que vinham do céu - fossem civilizações alienígenas ou soviéticos, que acabavam fundidos em mesclas alegóricas destes com aqueles (COLAVITO, 2008).

$\mathrm{Na}$ década de oitenta, com o progressivo arrefecimento das tensões políticas da Guerra Fria, a ficção de horror passará a figurar outros medos e angústias sociais. O período que será dominado pelo horror do corpo pode ser descrito como o produto de uma época em que os grandes avanços ocorridos no campo da ciência médica chocaram-se com a rejeição, disseminada pelos trabalhos de vários teóricos pósestruturalistas (SOKAL \& BRICMONT, 2014), ao conhecimento científico. À medida que a biotecnologia ocupava o lugar da energia nuclear e das viagens espaciais como a vanguarda da ciência, a narrativa de horror plasmava, no imaginário, novos tipos de monstruosidades.

Um conjunto de avanços tecnológicos pavimentou o caminho para a ascensão do horror do corpo. Vale mencionar, como exemplos, os transplantes de órgãos, que permitiram aos médicos combinar, ao modo de Victor Frankenstein, partes de diferentes indivíduos; a descoberta da pílula anticoncepcional e o nascimento do primeiro bebê de proveta, eventos que descolaram a reprodução do ato sexual, e viceversa; a clonagem animal e o consequente temor da clonagem de seres humanos; as técnicas de prolongamento de vida com aparelhos, pondo em dúvida os significados plenos de vida e morte; o avanço das cirurgias plásticas, permitindo a escultura de corpos; a revelação do código genético humano, com promessa a ela associada de serem desvendados os segredos da evolução; e, ainda, a criação de animais e vegetais geneticamente modificados, cujas consequências não eram - $\mathrm{e}$ ainda não são - suficientemente conhecidas (COLAVITO, 2008, p. 293-4). A soma desses impressionantes desenvolvimentos biotecnológicos criou condições ideais para que o corpo humano passasse a ser representado, na narrativa de horror, como fonte de ansiedade, de repulsa e de terror.

Em uma sociedade obcecada com o corpo - nas academias de ginástica, nas clínicas de cirurgia estética, nos corpos perfeitos na $\mathrm{TV}$, no cinema, nas propagandas e na pornografia -, não chega a surpreender o surgimento, na literatura, do que ficaria conhecido como Splatterpunk, um subgênero que explorou o horror corporal por meio do uso de linguagem obscena, 
descrições extremas de violência contra o corpo, combinação entre erotismo e mutilação corporal, e uma busca programática pela violência extrema e a sanguinolência (TUCKER, 1991).

De modo geral, as narrativas que exploram o horror do corpo valem-se, em menor ou maior escala, da violência gráfica, isto é, da descrição detalhada e realística de cenas e atos brutais - um procedimento artístico que se tornou recorrente em diversos produtos culturais nas últimas décadas. O uso explícito de cenas hediondas distinguirá a violência gráfica de outras formas de crueldade possíveis de se encontrar em obras artísticas e dará forma, no cinema de horror, a subgêneros como o Splatter e o Gore em que a violência é extrema e visceral até mesmo para os elevados padrões do gênero (McCARTY, 1984).

O horror do corpo é especialmente marcante nos filmes de Torture Porn, como são chamados os filmes que exploram, realística e ostensivamente, cenas em que a dor física e o terror emocional são produzidos por técnicas de tortura, com o intuito deliberado de produzir choques na audiência. $\mathrm{O}$ termo porn ressalta a frequência com que os atos praticados são de ordem sexual, e a violência empregada não visa matar a vítima, mas mantê-la viva pelo máximo de tempo possível, submetendo-a a flagelos excruciantes. Nesse tipo de trama, a submissão do corpo humano às mais terríveis aflições não são uma contingência, mas sim o próprio clímax narrativo e a fonte primária e central do horror artístico (MORRIS, 2012).

Os vilões do horror do corpo são, na imensa maioria das vezes, psicopatas assassinos, para quem o corpo humano se transformou em um macabro parque de diversões (COLAVITO, 2008, p. 319.). Quando há heróis, esses são indivíduos comuns, que tentam restaurar a ordem, mas, frequentemente, falham, impotentes, diante de um Mal que põe em xeque o valor da razão para orientar as condutas humanas. Do ponto de vista do enredo, proliferam o que podemos chamar de tramas "acidentais", em que uma ou mais personagens inocentes acidentalmente transgridem alguma fronteira (geográfica, social, cultural) e se tornam vítimas ocasionais de monstros - humanos, quase sempre - cuja existência desconheciam. Não raramente, nota-se a ausência absoluta de fabulações mais complexas em favor da exposição sensacional de sangue e vísceras - grande parte do apelo estético dessas obras repousaria justamente nas técnicas de recriação da violência, 
do sangue e das vísceras. Como muito bem observou o escritor norte-americano Fritz Leiber, não há explicações para a natureza do horror, não há relações de causalidade (apud COLAVITO, 2008, p. 305). Em sua crueza, tais enredos parecem apenas indicar a fragilidade do corpo humano e nos dizer que “o mundo é perigoso. Se você transgredir as fronteiras, você morre. E mesmo que você faça tudo certo, ainda assim você morre. E será uma morte horrível" (COLAVITO, 2008, p. 320). ${ }^{2}$

\section{O corpo humano como matriz de sofrimentos}

No tópico anterior, procurei traçar, em linhas muito gerais, as características do período que ficou conhecido como a era do horror do corpo. Para tanto, foi por mim ressaltada a influência exercida por elementos contextuais - de ordem histórica, cultural e social - na produção ficcional da época, materializada nas semelhanças observáveis em um conjunto significativo de obras de horror.

Os conteúdos das narrativas ficcionais de horror, contudo, não são alimentados exclusivamente por elementos eventuais e relativos. Sendo o medo uma emoção instintiva do ser humano, ele possui muitos gatilhos ligados a características atávicas, que remetem, muito provavelmente, aos primórdios da espécie humana. Em outras palavras, alguns motivos do horror possuem alcance mais universal, em termos antropológicos. Certas temáticas do horror (o medo do escuro; o medo de ser devorado; o medo do desconhecido; o medo da morte etc.), portanto, podem ser rastreadas nas mais diversas literaturas, dos mais diversos povos, nas mais diversas eras, uma vez que dizem respeito aos temores mais profundos da condição humana.

2 O sucesso comercial dessas narrativas apresenta instigantes desafios para reflexões sobre o sentido moral da arte. Tive oportunidade de me dedicar ao tema em dois artigos anteriores: "A educação pelo mal (ou para que servem as narrativas de horror?)" (FRANÇA 2015) e "A empatia nas estratégias narrativas do horror artístico: o caso Hitchcock" (FRANÇA, 2017a).
Ao enumerar, em $O$ mal-estar na civilização, as três possíveis causas do sofrimento humano, Sigmund Freud (1996) identificou as três fontes primordiais do horror atávico: nosso próprio corpo; o mundo externo; e nossos relacionamentos com os outros seres humanos. Os três são dimensões sempre exploradas como potenciais geradores do horror como efeito de recepção nas narrativas ficcionais. O Body Horror está, obviamente, relacionado ao primeiro deles - nosso próprio corpo, "condenado à decadência e à dissolução, e que nem mesmo pode dispensar o sofrimento e a ansiedade como sinais 
de advertência" (FREUD, 1996, p. 84-85). O corpo humano é um índice cabal da fragilidade e da brevidade de nossa existência. Nosso tempo de vida se inscreve nele, marcando-o, modificando-o e não permitindo que nos esqueçamos de nossa mortalidade. Ele e suas necessidades imperiosas, pouco indistintas das de qualquer outro animal, são âncoras a conter nossos desejos de transcendência.

Sem a pretensão de esgotar os modos de exploração do corpo humano na tradição da narrativa de horror, focalizarei duas ocorrências que, por seu caráter reincidente, são especialmente importantes: as representações do corpo como índice de degradação e de decadência, tanto física quanto moral; e as representações do corpo como o ponto limítrofe entre o cultural e o natural, entre o humano e o animal. Os dois contos de Gastão Cruls selecionados antecipam algumas características do que viria a dominar a ficção de horror das décadas finais do século $X X$, ao tematizarem justamente esses dois tipos de horror encarnados pelo corpo humano: o corpo como signo de nossa mortalidade, o corpo como signo de nossa animalidade. Escritos na primeira metade do século XX, e, portanto, fora do espectro do período que viria a ser conhecido como a era do horror do corpo, eles demonstram como o horror ficcional se alicerça, muitas vezes, em medos primordiais, profundamente arraigados na experiência humana.

\section{Mortalidade e animalidade: o horror do corpo em Gastão Cruls}

A primeira narrativa selecionada é "G.C.P.A.", um dos contos do livro Coivara (1920), de Gastão Cruls. A trama é simples e apresenta a história do enfermeiro Silvino, que adoece e é internado no próprio hospital onde trabalha. O protagonista torna-se então objeto de estudo do médico chefe dos residentes, Professor Rodrigues, e sofre com a frieza e a impessoalidade do tratamento que recebe. Quando descobre ser portador de uma doença rara e incurável, Silvino decide fugir do hospital para evitar que seu cadáver fosse destinado à autópsia.

Oelemento central da trama é o que poderíamos chamar de "descrença na ciência", uma variante de uma das estruturas mais recorrentes do horror ficcional: os "enredos de extrapolador" (CARROLL, 1990, p. 118-125). O tema do cientista incapaz de 
lidar com as consequências éticas de suas experiências faz-se presente em algumas das mais fundamentais obras da literatura gótica, como Frankenstein (1818), de Mary Shelley; Strange case of Dr Jekyll and Mr Hyde (1886), de Robert Louis Stevenson; e The Island of Dr Moreau (1896), de H. G. Wells, apenas para ficar nos exemplos mais óbvios.

No conto de Cruls, o protagonista irá se tornar vítima da amoralidade e da falta de empatia do cientista. Enquanto é examinado por Doutor Rodrigues, em presença dos estudantes, Silvino ouve a descrição detalhada de seu mórbido estado de saúde, feita com a frieza enigmática dos termos técnicos. Seu corpo é manipulado não mais como organismo vivo, mas como se fosse um objeto de estudo, e, apesar da "linguagem obscura e inescrutável" (CRULS, 1951, p. 35) do entusiasmado professor, o paciente, familiarizado com a terminologia médica, acompanha o diagnóstico: tratava-se de um sarcoma, um tumor maligno intratável. Para demonstrar seus argumentos, Rodrigues exibe, aos alunos, tumores semelhantes em órgãos guardados em formol:

[...] quatro ou cinco frascos de vidro grosso conservavam mergulhados num líquido turvo e sanioso, órgãos e vísceras de outros doentes que por ali já haviam passado, deixando bocados de si em pábulo à ciência. Intrometendo o punho arremangado por um desses largos bocais, o professor expôs ao olhar perspícuo dos presentes, uma das peças mais curiosas da sua coleção. Era a mão de um desgraçado, que se finara por uma sarcomatose generalizada, e que tinha a sua palma esburgada até os ossos pelo mal roaz e proliferante. Cortada cerce pelo punho, a pobre mão parecia ainda reter, entre os dedos grossos e nodosos a se engrifarem ameaçadoramente, todo o exaspero e dor do último estorcegão que a imobilizara (CRULS, 1951, p. 35).

Os efeitos de repulsa e de horror alcançados pela descrição valem-se, em grande medida, dos interditos que cercam o corpo humano. Como ele, de fato, funciona? Como ele se cura? Como ele se degrada? Todos esses processos, que vão sendo lenta e paulatinamente desvendados pela ciência médica, são desconhecidos pela maioria dos indivíduos, o que torna o corpo humano adoecido algo perturbador, por ser degenerado, isto é, algo alterado em suas qualidades fundamentais. $\mathrm{O}$ corpo enfermo, em sua semelhança grotesca com o corpo saudável, funciona como um poderoso lembrete 
de nossa finitude e fragilidade. O excerto seguinte, que narra as agruras do protagonista a ser examinado pelos discípulos de Rodrigues, mostra como o corpo degradado pode funcionar como índice da morte nas narrativas de horror:

Num torpor espásmico, já incapaz de reação, Silvino deixou que mais uma vez examinassem as suas misérias; e sob os dedos ágeis que percutiam e apalpavam o seu corpo, ele tinha o sangue regelado, numa prematura sensação de vermes que lhe mordicassem sequiosamente as carnes (CRULS, 1951, p. 38, grifo nosso).

Silvino experimenta as sensações da degradação de seu corpo, na analogia entre o "bando jovial” (CRULS, 1951, p. 38) de futuros doutores e os vermes necrófagos da decomposição. A cena antecede a anagnorisis que dá nome ao conto. Ao consultar seu prontuário, Silvino identifica a "abreviatura sinistra" (CRULS, 1951, p. 38), G.C.P.A., cujo significado é guarde o cadáver para autópsia. Versado nos jargões do mundo médico, o protagonista reconhece a sigla e, por conseguinte, o destino que será dado a seu corpo.

Certo de que a cura lhe seria impossível, Silvino busca ao menos livrar seu corpo dos abusos e tormentos da autópsia. Decide fugir do hospital, uma tarefa árdua, dado o seu debilitado estado de saúde. O doente era impelido, todavia, por suas lembranças, já que lhe acudiam “à memória, com uma precisão terrificante de particularidades, algumas das autópsias a que ele assistira e mesmo auxiliara" (CRULS, 1951, p. 40). Suas reminiscências são apresentadas pelo narrador com todos os pormenores cruéis típicos do horror do corpo:

Para a retirada do sistema nervoso abriram-lhe o crânio ao meio, esnocaram vértebra por vértebra. Ao cabo de duas horas de porfiante tarefa, em que serras e escopros se sucediam, as mãos de dois internos, a medula surgiu numa tripa languinhenta e acinzentada, cheia de ramificações laterais, à semelhança de um miriápode de proporções desmesuradas. Durante todas essas manobras, o morto, deborcado sobre o mármore, tinha a cabeça a balouçar de um cepo, e a boca entreaberta deixava escorrer uma baba esverdongada e pestilencial (CRULS, 1951, p. 41).

Na sequência final do conto, a aflitiva fuga do enfermeiro tem, por fim, seu desfecho, quando Silvino, de um quebra-mar, lança-se às ondas. Seu último desejo, porém, não se realiza: 
a maré devolve o corpo à praia, de onde será conduzido, inevitavelmente, à mesa de autopsia e ao destino de ter algumas de suas partes preservadas como objetos de estudo.

"G.C.P.A.", por um lado, explora horrores primordiais, ao abordar o poderoso tabu da perda do direito à inumação, presente na literatura ocidental pelo menos desde o dilema enfrentado pela protagonista de Antígona, de Sófocles. Por outro, o conto obtém muitos de seus efeitos de horror e de repulsa simplesmente por meio da descrição minuciosa de partes do corpo humano. Tanto o sucesso desse procedimento, característico das narrativas de body horror, quanto o potencial fóbico do corpo humano podem ser explicados, em parte, pela suscetibilidade do homem moderno ao corpo enfermo. A própria relação que estabelecemos com a fisiologia de nosso corpo é asséptica: somos tratados em hospitais, por técnicos, e mesmo as carnes animais que consumimos vêm envoltas em pacotes plásticos, preservando-nos dos cheiros, dos sons, da violência inerente à morte e à degradação corporal.

O conto seguinte irá explorar uma outra dimensão do horror do corpo, aquele associado à condição animal do corpo humano. Trata-se de um tipo de horror que ganhou força em fins do século XIX, e nele sempre se percebem ecos do efeito avassalador de On the origins of species by means of natural selection (1859), de Charles Darwin, sobre as mentalidades modernas. A ideia darwiniana de que a competição por vantagens reprodutivas era a principal alavanca das mudanças das espécies levou, no senso comum, à percepção de que a natureza era inevitavelmente hostil e confrontativa. Em consequência, as ameaças do Mal metafísico da literatura gótica do século XVIII, que tantas vezes tomavam formas sobrenaturais alegóricas, como fantasmas e aparições, derem lugar ao monstro como um ser corpóreo, algo no continuum entre o homem e animal.

Consolidava-se, paulatinamente, a ideia de que à espécie humana não cabia a posição privilegiada na grande cadeia dos seres proposta pela tradição judaico-cristã. Tal percepção foi incrementada ainda pelos trabalhos de criminologistas como Cesare Lombroso, cujas teses defendiam a hipótese de que alguns indivíduos eram mais primitivos e bestiais do que outros. Logo, a origem dos males podia estar dentro, e não fora, de nós, seres humanos, em razão de características inerentes à nossa própria natureza. 
Como bem observou Camille Paglia (1992, p. 15), o sexo é justamente "o ponto de contato entre o homem e a natureza, onde a moralidade e as boas intenções caem diante de impulsos primitivos". Não por acaso, as obras modernas de horror - e, mais especificamente, as narrativas de horror do corpo são repletas de conteúdos sexuais. Nas palavras de um dos principais escritores do gênero: "O sexo é uma pequena loucura - e com que frequência o horror é sobre a loucura? O sexo é uma pequena morte - com que frequência o horror é sobre a morte? O sexo é sobre o corpo - com que frequência o horror é sobre o corpo?" (BARKER, 1985, p. 216. Tradução minha). Tomado muitas vezes como uma ameaça ao equilíbrio das sociedades humanas, o complexo campo das relações sexuais tem seu potencial fóbico explorado em representações que investem no que nele pode haver de perigoso, degradante e letal (cf. SILVA, 2017, p. 150).

Em "O espelho", conto do livro História puxa história (1938), Gastão Cruls explora a temática da repulsa ao sexo para construir uma genuína história de horror. A narrativa abre com uma reminiscência do narrador-protagonista, do alerta que fizera a Isa, sua esposa: "Bem que eu lhe dizia: - Não compre esse espelho. Isso não é móvel para casa de gente séria" (CRULS, 1951, p.339). O espelho em questão, que dá nome ao conto, fora arrematado em um leilão, e pertencera a "uma das mais famosas mundanas do seu tempo" (CRULS, 1951, p.339).

De início, o espelho despertou pura aversão no narradorprotagonista. Porém, após ser instalado em frente à cama do casal, o móvel, um extravagante tríptico, acaba por transformar a vida sexual tanto de Isa quanto de seu marido:

\footnotetext{
Não só a Isa mas a mim também, contagiara o mesmo ardor da carne eternamente insatisfeita, dos lábios que não se dessedentam, dos sentidos que não se atreguam. O sangue que nos raivava nas veias pedia volúpias novas, requintes nunca dantes experimentados (...). Mas cedo também me dei conta que àquele despertar dos sentidos surgira nela uma verdadeira bacante, abrasada de desejos, ávida de prazeres, e perfeitamente iniciada em todos os segredos da volúpia (CRULS, 1951, p. 343).
}

Qual fosse um artefato amaldiçoado, que cobrasse por meio de efeitos colaterais os benefícios que provê, o espelho desencadeia deleites que rapidamente se convertem em aflição. 
A manifestação de um desejo sexual intenso e multifacetado em Isa afeta negativamente o narrador-protagonista, que, oscilando entre o assombro e o receio, passa a ser vítima de um complexo e doentio sentimento: ele sente ciúmes de si próprio, ou, melhor dizendo, de sua própria imagem refletida pelo espelho:

Dir-se-ia que daquelas folhas de vidro estanhado se projetavam sobre a nossa cama todas as cenas de abominação e luxúria, todos os vícios e torpitudes que nelas se haviam fixado durante o tempo em que tinham estado a serviço da cortesã. Assim, conforme só tardiamente pude certificar-me, a minha figura, projetada sobre o cristal polido e agindo à maneira de um "revelador", trazia-lhe à superfície qualquer das muitas imagens que indelevelmente se haviam fixado nas suas folhas. E de tal modo que elas tomavam o meu lugar, davam-me outro aspecto físico, faziam de mim um indivíduo totalmente diverso do que sou [...] (CRULS, 1951, p. 344).

Em sua paranoia - que, diga-se de passagem, é uma característica recorrente dos narradores de horror -, o protagonista supõe-se traído pelas imagens que, supostamente, Isa contemplava no espelho, isto é, por aquilo que o espelho a incitava imaginar. O progressivo incremento das desconfianças do protagonista atinge seu clímax no desfecho do conto, quando, certa noite, no auge do arrebatamento de um ato sexual, o espelho racha diagonalmente:

As suas duas faces laterais, que nada haviam sofrido, reproduziam-me a imagem com nitidez. Era bem o meu rosto que ali estava, de tez macilenta, traços longos e puxados. E bem o meu corpo escanifrado, de costelas à mostra e pelo ralo. No centro, porém, desafiava-me a figura do outro. Digo do outro, porque nada tinha de mim, a não ser os gestos. Um animalaço bem arcabouçado, de gorja taurina e peito ancho. E lanzudo como um fauno. (...) Que figura miserável fazia eu diante daquele rival viripotente! (...) E assim se explicava por que Isa mudara tanto. Era com aquele e outros que ela se abrasava entre os meus braços (CRULS, 1951, p. 347).

O protagonista contempla, diante de si, refletido na superfície rachada do espelho, uma imagem que ele não reconhece como sendo o reflexo dele próprio. Diante daquele duplo de aspecto animalesco, ele é tomado por um frenesi de fúria. Espatifa o espelho e arremessa a esposa violentamente sobre os destroços. As últimas linhas do conto, abaixo descritas, são um bom exemplo do horror do corpo na literatura: 
O espelho já se fizera em pedaços, mas a figura continuava presente e em cada caco havia bocados dela. E aquele sangue, que salpicava tudo, de onde viria? Acaso o infame, ao ser assim estraçalhado, se esvaía por todas as veias? Quem sabe lá? Mas vinha também de mim, já de pés e mãos encarniçados. E ainda de Isa, sobre cujo corpo eu caíra, munido de um estilhaço pontiagudo, e no qual ia abrindo, com volúpia, profundos e mortais rasgões (CRULS, 1951, p. 347-8).

No conto de Cruls, são as imagens do corpo animalizado refletido pelo espelho que alertam para os riscos da perda do controle e do retorno do homem à sua natureza selvagem $\mathrm{e}$ indomesticável. O sexo é a potência primordial, capaz de nos arremessar de volta ao nosso estado natural por excelência: a barbárie, o caos. E o grande paradoxo é que esse terrível mal é capaz de nos dar prazer.

Os dois contos de Cruls serviram como demonstração de que os mecanismos do horror do corpo fazem-se presentes mesmo em narrativas que não podem ser descritas como características do gênero, em seu sentido estrito. Grande parte da singularidade do apelo desse subgênero é que ele não aborda temas restritos às formas mais comuns do horror, que se valem de elementos francamente sobrenaturais - não se trata de corpos mortos ou cadáveres que voltam à vida. Como defende o diretor de cinema Stuart Gordon, na epígrafe que abriu este ensaio, esse tipo de narrativa é inquietante porque fala sobre o nosso próprio corpo e sobre como algo muito errado pode estar acontecendo com ele - dentro dele - a todo e a qualquer momento. O Body Horror é, portanto, sobre como nosso corpo pode nos trair, e sobre a angústia de, estando presos a ele, não termos como dele fugir.

\section{REFERÊNCIAS}

BARKER, Clive. Interview. In: WINTER, Douglas E. Faces of fear; encounter with the creators of modern horror. New York: Berkley Books, 1985. p. 207-220.

CARROLL, Noël. The philosophy of horror or the paradoxes of heart. Nova York: Routledge, 1990. 
COLAVITO, Jason. Knowing Fear; Science, knowledge and the development of the horror genre. Jefferson: McFarland, 2008.

CRULS, Gastão. O espelho In: Contos reunidos. Rio de Janeiro: José Olympio, 1951. p. 339-348.

G.C.P.A. In: . Contos reunidos. Rio de Janeiro: José Olympio, 1951. p. 31-43.

FITZPATRICK, Claire, ed. The Body Horror Book; essays of the macabre. Brisbane: Oscillate Wildy Press, 2017.

FRANÇA, Júlio. A educação pelo mal (ou para que servem as narrativas de horror?). In: SANTOS, Josalba, JEHA, Julio, Org. Sobre o Mal. Curitiba: Appris, 2015. p.147-162.

A empatia nas estratégias narrativas do horror artístico: o caso Hitchcock. In: ROSSI, Cido; ZANINI, Claudio. Vertigo. Rio de Janeiro: Bonecker, 2017a. p. 21-38

. Medo e literatura. In: ., org. Poéticas do Mal: a literatura do medo no Brasil (1840-1920). Rio de Janeiro: Bonecker, 2017b. p. 36-52.

FREUD, Sigmund. O mal-estar na civilização. In: . Obras psicológicas completas de Sigmund Freud; edição standard brasileira. Vol. XXI. Rio de Janeiro: Imago, 1996. (p. 73-148)

GORDON, Stuart. Body horror. In: KANE, Paul, O'REGAN, Marie, ed. The Mamoth Book of Body Horror. London: Constable \& Robinson, 2012.

McCARTY, John. Splatter Movies: breaking the last taboo of the screen. New York: St. Martin's Press, 1984.

MORRIS, Jeremy. The justification of torture-Horror. In: FAHY, Thomas, ed. The Philosophy of Horror. Kentucky: University of Kentucky Press, 2012. p. 42-56.

PAGLIA, Camille. Personas sexuais: arte e decadência de Nefertite a Emily Dickinson. São Paulo: Companhia das Letras, 1992. 
SILVA, Daniel Augusto P. Horror sexual e ficção decadente. In: FRANÇA, Júlio (Org.). Poéticas do Mal: a literatura do medo no Brasil. Rio de Janeiro: Bonecker, 2017. p. 150-177.

SOKAL, Alan, BRICMONT, Jean. Intermezzo: O relativismo epistêmico na filosofia da ciência. In: Imposturas intelectuais: o abuso da ciência pelos filósofos pós-modernos. Rio de Janeiro: Bestbolso, 2014. P. 61-108.

TUCKER, Ken. The splatterpunk trend, and welcome to it. New York Times. 24 de março de 1991. Disponível em: https://www. nytimes.com/1991/03/24/books/the-splatterpunk-trend-andwelcome-to-it.html. 


\section{Abstract \\ The Body Horror in Two Short Stories by Gastão Cruls}

The essay aims to examine the human body as a source of horror in literature. More specifically, we seek to describe the ways in which the human body is represented in horror narratives. In order to do so, we discuss the body horror as a narrative tradition that exploits the fear we feel of our own body. The works to be examinated are Gastão Cruls' (1888-1959) short narratives "G.C.P.A." (1920) and "O espelho" (1938).

Keywords: Comparative Literature; Gothic Literature; Horror Literature. 